\title{
Review of Condition Assessment Methods for Subsea High Voltage Components
}

\author{
Dmytro Kulagin, Frank Mauseth, and Erling Ildstad \\ Department of Electric Power Engineering, NTNU, Trondheim, Norway
}

\begin{abstract}
This paper presents a review on condition assessment of some of the most critical components in the power grid today, such as transformers, rotating machines and cables and their accessories. The main purpose is to identify methods that can be applicable for high voltage equipment for subsea use. The question addressed is what diagnostic tools should be used to detect apparatuses with a high probability of failure during service.

It is shown that today, only distributed temperature sensing systems are used for subsea applications. At the same time, the majority of condition assessment techniques used onshore can be adjusted for subsea use, particularly methods applicable for on-line monitoring.
\end{abstract}

\section{Introduction}

The overall purpose of condition assessment of a power system is to ensure a long life of the grid at a minimum of cost. This is challenging considering the many different kinds of electrical, mechanical, thermal and environmental stresses, which vary in amplitude and frequency of occurrence during the service life. In addition, random stresses due to overvoltages, rapid temperature changes and external mechanical impacts may cause unexpected damage. Thus, it becomes challenging to accurately estimate the rate of degradation and the remaining lifetime of a power apparatus. Also, the stresses acting on subsea equipment are different than equipment onshore, making it increasingly important to monitor the equipment.

In general, condition assessment can usually be performed either removing a component from operation (off-line) or doing on-line monitoring, either periodically or continuously during operation. Due to the remoteness of subsea power apparatuses and challenges with installation/removing, continuous online monitoring seems to be the preferred option for subsea power grid.

Thus, the criteria for a monitoring system for subsea use can be summarized as:

- On-line.

- $\quad$ Simple and endurable.

- $\quad$ Limited space for additional equipment.

- Harsh environment with salt water and high hydrostatic pressure.
The aim of this paper is to review available monitoring methods for power equipment and to form a base for future development of subsea applications.

\section{What can go wrong?}

In the following, a brief overview of possible failure modes is presented.

\subsection{Defects}

Different defects that often can be considered as contaminants can be introduced into the power apparatuses during production, installation and maintenance. Introduced defects like voids/cavities, bad adhesion between insulation and electrodes, contaminants, etc. can all contribute to reduce the lifetime of power equipment.

Connectors are critical components in any power grid providing changeable links between junction boxes, platforms, transformers, nodes, etc. The metallic contacts are subjected to both dynamical mechanical stresses and chemical corrosion. Improper mating causing displacement, or an angle between the electrodes, may result in locally high current densities and increased resistive losses and excessive heating. During mating, water, sand and silt might also enter into the connector that may also result in erosion of the electrode surfaces or/and insulating materials.

\subsection{Excessive warming and hot spots}

There are several causes that can lead to excessive warming of power apparatuses. Overloading of the system or high contact resistance, will lead to an increase in the resistive losses and heat generation. If the generated heat is higher than what is dissipated, the insulation system might be damaged and in worst case, a thermal breakdown can occur.

To avoid any risk of overheating, cooling systems are used in different power apparatuses, such as rotating machines and transformers. Any defects in the cooling system will result in a temperature increase that might be critical.

During excessive heating, softening or melting of solid insulation and formation of gases are possible. As a result, voids may be formed in solid or liquid insulation resulting in partial discharges (PDs) and electrical degradation. 


\subsection{Water ingress}

Even though the design of HV equipment is engineered to prevent water ingress, intrusion of water cannot be excluded during service and operation, due to improper mating of connectors, leakages and diffusion of water through sealings or small cracks etc.

Humidity has an influence on the dielectric properties of insulating liquids. Water is normally dissolved in liquid dielectric, but when the water content of the dielectric oil reaches the saturation limit, free water droplets are formed that lead to a rapid decrease of the breakdown strength. Even in the case of a water content well below the saturation limit, the breakdown strength of the insulation can be considerably reduced [1]. For instance, AC breakdown voltage of synthetic ester Midel 7131 is typically reduced by $50 \%$ when the relative humidity is increased from 0 to $37 \%$ at $20^{\circ} \mathrm{C}$.

Increased water concentration in insulation will also result in increased resistive current through the insulation. Likewise, formation of thin water films on the insulation surface can result in high conductivity and currents causing resistive losses along the interfaces. In addition, dry zone formation cause uneven voltage distribution that can lead to surface discharges. Temperature variation can also lead to condensation of dissolved water, forming water droplets. Water droplets on an insulation surface can also lead to PDs and tracking [2], but also free water droplets in a dielectric liquid can cause PDs and carbonization of the dielectric liquid.

\subsection{Partial discharges}

Partial discharges are localized electrical discharges that only partially bridges the insulation between the electrodes and which can occur in voids inside the insulation or adjacent to a conductor [3]. Also, sharp edges, water droplets and other defects in the power equipment that can lead to and local field enhancement may cause PDs that eventually might lead to breakdown.

\section{Monitoring techniques overview}

\subsection{Temperature measurements}

According to ref. [4], thermocouples are undoubtedly the temperature sensors that are most widely used for monitoring. Such sensors are rugged, reliable, and reasonably accurate. Thermocouples are pairs of conductors of different materials, using the thermoelectric effect for temperature measurement. The data acquisition systems associated with thermocouples are also reliable and have been around for decades. Thermocouples can provide high accuracy of measurements up to $0.1{ }^{\circ} \mathrm{C}$ [5]. An alternative approach is to use resistance temperature detectors and thermistors. They are based on the dependence of the electrical resistance of metals, alloys and semiconductor materials of the temperature. RTDs have almost linear characteristic for metallic work elements, and have a theoretically accuracy up to $0.00013^{\circ} \mathrm{C}$. [6]. They are, however, more fragile and require an external power source.

\section{On-shore examples:}

In order to perform predictive maintenance of power equipment and to withdraw or repair any defective units before failure, IR-thermography are used for overhead lines [7-8], transformers [9-10], rotating machines [1112]. The working principle is based upon photon detection of the infrared radiation emitted by the warm bodies in the wavelength range of 2-15 $\mu \mathrm{m}$. The intensity of the thermal radiation of the body increases with the temperature. IR-thermography allows to visualize images and to compare temperature distribution over a large area. However, it is limited to surface temperature measurements only.

Detection and location of hot spots along a cable route is done by distributed temperature sensing (DTS) [1319]. Optical fibre systems can also be used to measurement of physical quantities, such as temperature, pressure and elongation. Optical fibre sensors have some advantages such as 1) they are passive and neutral in the system; 2) do not generate heat; 3) they are insensitive to electromagnetic interference; 4) examples show they can give local distribution of the temperature (up to $20 \mathrm{~km}$ ), and precise localization of the hottest places (up to $0.5 \mathrm{~m}$ ). However, complex techniques often have to be used for treatment of the signals [20]. It is worth to notice, that DTS systems already are in use for subsea cables [21].

Common failure modes for transformers that cause a temperature increase are overloading, hotspots from soldered and other joints and defects in the cooling system. Excessive heating leads to thermal ageing of the insulation that can result in breakdown. In order to avoid a breakdown, different temperature measurements are performed, such as temperature distributed sensing [20-21], and thermocouples [22-23] i.e. As an example of temperature measurements of the oil, thermocouples were used in [23]; thermocouple sensors were installed under the top of the transformer tank, in the on- and outlet pipe through which oil flows to the cooling radiator. To measure the temperature of the windings, optical fibre sensors was used.

Modern rotating machines normally have at least a few temperature sensors which can be continuously monitored. Typically thermocouples [13], thermoresistances [13], [24-25] and optical fibre [13], [26], are used for temperature monitoring in rotating machines. The sensors are used to measure the temperature at specific locations:

- Within the stator winding.

- Within cooling ducts. 
- Stator core.

- Stator frame.

In rotating machines, measurements of the rotor winding resistance can be used as a temperature sensor [27]. In case of synchronous machine rotor windings that employ slip rings, the voltage and current of the slip rings can be accurately measured, allowing the rotor winding resistance to be calculated from Ohm's law.

\subsection{Water content measurements}

Capacitive hygrometers and resistance moisture sensors can be used for water content measurements. The principle of capacitive sensor operation is based on change in permittivity of the sensor as water diffuses into the element. Due to the time needed for water to diffuse into the working element, it is important to notice that such sensors will have a time delay in the response.

Resistive moisture sensors measure changes in a humidity absorbent medium. The change of resistance is usually inversely dependent of the humidity [28]. Typical construction of such a sensor is a substrate with metallic electrodes, where the substrate is coated with a salt or a conductive polymer. The sensor absorbs external moisture leading to a higher electrical conductivity. The benefit of the resistive humidity detectors is complete interchangeability. However, they are sensitive to chemical pollutions and contamination of the oil. Resistive sensors are highly temperature dependent, and therefore, require temperature compensation.

IR-spectroscopy can be considered an alternative online technique for measurements of water content in dielectric liquids [29], using for example the broad water absorption band around $2745.74 \mathrm{~nm}$.

There are several methods aiming at measuring the dielectric response and dielectric loss factor $(\tan \delta)$ using DC voltages or variable frequency AC voltages [30]. Measurements in time domain are based on application of a DC voltage for a certain time, typically more than 10 minutes. During this time, the polarization current of the insulation will decrease towards a stable value. After charging, the high voltage is switched off and test object is short-circuited. Then the depolarization current or the return voltage is measured. Alternatively, the frequency domain can be used, subjecting the system to a sinusoidal AC voltage with variable frequencies. By measuring the applied voltage and the resulting current, the capacitance of test object and dielectric loss factor can be calculated. As $\tan \delta$ is dependent on the conductive losses, an increase in the relative humidity will lead to an increase in the loss factor. Results presented in [31] show that a relative humidity above $1.5 \%$ in oil-impregnated paper insulation, leads to a strong increase in the $\tan \delta$ loss factor.
Review of monitoring techniques for detecting and measuring of water content has shown that several methods can be used. In case of power cables, electrical water sensors are usually integrated in the cable screen [32].

\subsection{PD measurements}

The energy released during a PD will result in electrical pulses, acoustic pulses, light, as well as chemical reactions. Thus, there is a wide range of PD detection methods that for practical reasons are divided into electric, electromagnetic or remote microwave method, acoustic, chemical, optical or optoelectronic, and thermal techniques.

One of the challenges with PD measurements is related to the demands to detect and to measure discharges of only a few picocoulombs in an environment where background noise always is present. Small currents will flow in the circuit every time a PD occur, because discharge is accompanied by a flow of electrons and/or ions across a volume. The current pulse can be measured in an external circuit, where it will convert into a voltage pulse over a measurement impedance. Using voltage phase and time resolved measurements it is also possible to characterize the PDs.

The current pulse measurement method requires that a measurement impedance need to be connected to parts of the equipment. In addition, a coupling capacitor is needed. Alternatively, capacitive sensors based on a "bridge arrangement" can be used where e.g., a cable joint is divided in two parts with the same capacitance and the difference in signals is measured [33-34]. The sensitivity of the measurements also depends on the capacitances involved, and at large capacitances, the sensitivity becomes low. In places with background noise, other methods such as acoustic methods might be more sensitive.

Acoustic methods for detection of PDs was designed to locate the site of the PDs, for example, in power and instrument transformers and gas-insulated equipment. The apparent simplicity of the method does not exclude the great difficulty in determining the place of origin of the PD. To locate them, sensitive microphones can be used which pick up sound waves located in the frequency range above $55 \mathrm{kHz}$. Disadvantages are low sensitivity at low PD levels and large attenuation of the acoustic pulses when travelling through the insulation materials.

For PD measurements, high frequency measurements are also often used. The high frequency current transformer (HFCT) that has a wide-band pulse response is designed specifically for picking up PD signals in ground loops. The current transformer is constructed of a ferrite core and is usually encased in a metal housing. The durable body has usually a hinge 
and a quick release latch, making use quick and easy. In some applications, additional insulation is required between the HFCT housing and the measured conductor.

A variety of standards gives guidelines and requirements how to perform PD measurements: [3, 3440]. Guidance and recommendation over implementation of PD measurements on the cable setups can be found in [41-45].

\section{Discussion}

\subsection{Temperature measurements}

The range of widely used temperature measurement techniques includes thermocouples, RTD, DTS systems, and thermography. The main advantage of DTS systems over the thermocouples and RTD is that they allow distributed temperature sensing. They are all robust and can withstand high hydrostatic pressures. Thermocouples and RTD are also very compact sensors, allowing measurements to be performed in small oil volumes etc. IR-thermography however, as it is restricted to measurements of surface temperatures, is not suited for subsea applications.

\subsection{Water content measurements}

Both capacitive hygrometers and resistance moisture sensors seems suitable for application in subsea power equipment. They are compact and reliable, and should be able to withstand the high hydrostatic pressure.

The use of IR-spectroscopy for water content measurements is another possibility, but spectroscopes for IR analysis requires a relatively large volume. However, it is not necessary to measure over the entire IR-spectrum in order to be able to detect water. Compact IR diodes with certain wavelengths of illumination and accompanying sensors can be used instead of the large sized spectroscopes. As mentioned in chapter 3.2, IR diode and detector with a working wavelength of $2745.74 \mathrm{~nm}$ can be used for water content measurements in synthetic ester Midel. However, when using the same wavelength for the nonpolar mineral oil Nytro, there is no readable change in the absorbance. In Nytro there is a small change in the absorbance at $5717.55 \mathrm{~nm}$ that may be used for water detection. The difference between the two oils is mainly due to the difference in water absorption capability. Thus, IR spectrometry can be used for water content measurements in polar esters such as Midel, where water can dissolve easily and can reach concentrations of $700-1100 \mathrm{ppm}$ before saturation at a temperature around $0{ }^{\circ} \mathrm{C}$. For non-polar mineral oils and slightly polar silicone oils, the use of IR spectroscopy can be difficult as these liquids does not absorb much water before saturation; around $10 \mathrm{ppm}$ for mineral oil and $100 \mathrm{ppm}$ for silicone oil at a temperature around $0{ }^{\circ} \mathrm{C}$. Thus, their IR spectra do not show any significant changes in the absorption due to small amount of dissolved water.

It is also important to notice that the water sorption is strongly dependent on the temperature. Thus, humidity measurements should be accompanied with temperature measurements in order to be able to determine the criticality of the relative humidity, i.e. going from a full load situation to a non-load situation with a decrease in temperature as result.

Humidity can also be detected using dielectric response. Humidity can be seen as an increase in the dielectric losses, but it is not possible to link the increase to a certain level of humidity. Also, aging and other phenomena can lead to an increase of the losses. Any equipment has to be disconnected from the power grid, as a variation of voltage levels and frequencies has to be applied. Another limitation is the apparent power needed to preform measurements. Dielectric response can be used as an indication of ageing of the equipment.

\subsection{PD measurements}

As PDs release energy in different forms, a number of the phenomena can be used to detect and/or measure the value of the discharge. Some of the methods have some limitations in their usability. For example, detection of light emission is useful for outdoor HV equipment and accessories. However, for subsea applications it will not be useful as PDs will be internal in the insulation system.

The heat developed is also very limited and, as for onshore applications, difficult or impossible to measure and detect.

Detection of electric pulses seems to be the most promising method for subsea use. The balanced circuit method can be used as well as the more classical electric detection method. However, the latter requires a form of coupling capacitor that might be spacious. In addition, the measurement equipment itself is advanced and may not be well suited for subsea use. Another method based on electric pulses is using a high frequency sensor that easily can be attached around i.e. a cable. They are very simple and do not add to the complexity of the high voltage design. In addition, acoustic sensors might be used, but attenuation of the signals make the usability limited. However, in some cases, it might be preferable to electric pulse measurements.

As PDs lead to chemical changes in the insulation, performing chemical analyses like dissolved gas analysis (DGA) of dielectric liquids is useful on-shore, but as oil samples have to be taken, it is considered as an off-line method and unsuited for subsea applications. Alternatively to DGA, spectroscopy methods in the IRrange can be used on-line in order to perform chemical monitoring [46]. This equipment can be made relatively small and be a possible solution. However, as this type of equipment so far has not been used under high hydrostatic pressures, further investigation is needed. 


\section{Conclusion}

Review has shown that only distributed temperature sensing systems are already used in subsea application, but at the same time, the majority of the condition assessment techniques used onshore seems suited for offshore use.

\section{Acknowledgments}

This work is performed as part of common NTNUSiemens project on condition assessment of electrical power systems and components. The authors would like to thank Siemens Oil and Gas Divisions, Norway in providing financial support for this project.

\section{References}

[1] Martin R., and other, Experiences in Service with New Insulating Liquids, CIGRÉ A2-35, 2010.

[2] S. Kumagai, and N. Yoshimura, "Polydimethylsiloxane and Alumina Trihydrate System Subjected to Dry-band Discharges or High Temperature Part I: Chemical Structure”, IEEE Transactions on Dielectrics and Electrical Insulation, Vol. 11, No. 4, 2004, pp. 691-700.

[3] IEC 60270, High-voltage test techniques - partial discharge measurements, 2000.

[4] IEEE Std. 1718-2012, Guide for Temperature Monitoring of Cable Systems, 2012.

[5] Burns G.W., and Scroger M.G., NIST Measurement Services: The Calibration of Thermocouples and Thermocouple Materials, U.S. Government printing office, Washington, 1989.

[6] Agilent Technologies, Practical temperature measurements - Application note 290, USA, 2012.

[7] Weibel M., Sattinger W., Rothermann P., Steinegger U., Zima M., and Biedenbach G. Overhead Line Temperature Monitoring Pilot Project, CIGRÉ B2-311, 2006.

[8] J. Pinto, M. Masuda, L. Magrini, J. Jardini, and M. Garbelloti, "Mobile robot for hot spot monitoring in electric power substation”, Transmission and Distribution Conference and Exposition, 2008, pp. 1-5.

[9] N. Utami, Y. Tamsir, A. Pharmatrisanti, H. Gumilang, B. Cahyono, and R. Siregar, "Evaluation condition of transformer based on infrared thermography results", IEEE 9th International Conference on the Properties and Applications of Dielectric Materials, 2009, pp. 1055-1058.

[10] R. Yadav, S. Kumar, A. Venkatasami, A. Lobo, and A. Wagle, "Condition based maintenance of power transformer: a case study”, International Conference on Condition Monitoring and Diagnosis, 2008, pp. 502-504.
[11] A. Widodo, D. Satrijo, M. Huda, G.-M. Lim, and B.-S. Yang, "Application of self organizing map for intelligent machine fault diagnostics based on infrared thermography images”, International Conference on Bio-Inspired Computing: Theories and Applications, 2011, pp. 123-128.

[12] S. Stipetic, M. Kovacic, Z. Hanic, and M. Vrazic, "Measurement of excitation winding temperature on synchronous generator in rotation using infrared thermography”, IEEE Transactions on Industrial Electronics, Vol. 59, No. 5, 2011, pp. 2288-2298.

[13] C. Hudon, M. Levesque, L. Zou, and J. Picard, "Determination of stator temperature profile using distributed sensing”, IEEE Electrical Insulation Conference, 2013, pp. 191-195.

[14] W. Gan, and Y. Wang, "Application of the distributed optical fiber grating temperature sensing technology in high-voltage cable”, International Conference on Electronic and Mechanical Engineering and Information Technology, Vol. 9, 2011, pp. 4538-4541.

[15] H. Li, K. Tan, and Q. Su, “Assessment of underground cable ratings based on distributed temperature sensing”, IEEE Transactions on Power Delivery, Vol. 21, No. 4, 2006, pp. 17631769.

[16] L. Yuan, L. Tao, S. Zhihui, W. Chang, and L. Tongyu, "Application of distributed optical fiber temperature system in online monitoring and fault diagnosis of smart grid", Power and Energy Engineering Conference, 2012, pp. 1-4.

[17] Q. Jiang, and Q. Sui, "Technological study on distributed fiber sensor monitoring of high voltage power cable in seafloor”, International Conference on Automation and Logistics, 2009, pp. 11541159.

[18] M. Schmale, R. Puffer, U. Glombitza, and H. Hoff, "Online Ampacity Determination of a 220-kV Cable Using an Optical Fibre Based Monitoring System”, International Conference on Insulated Power Cables, 2011, pp. C.9.3.

[19] G. Yilmaz, and S. E. Karlik, “A distributed optical fiber sensor for temperature detection in power cables”, Sensors and Actuators A: Physical, Vol. 125, Iss. 2, 2006, pp. 148-155.

[20] D. Yu, L. Jing, W. Shengbin, Z. Aide, Z. Hesan, and Z. Chao, "Study on on-line monitoring of temperature of transformer winding based on distributed fiber optical temperature sensing technology", International Conference on Properties and Applications of Dielectric Materials, 2006, pp. 253-256.

[21] A. Ribeiro, N. Eira, J. Sousa, P. Guerreiro, and J. Salcedo, "Multipoint fiber-optic hot-spot sensing network integrated into high power transformer for continuous monitoring”, IEEE Sensors Journal, Vol. 8, No. 7, 2008, pp. 1264-1267.

[22] N. Utami, Y. Tamsir, A. Pharmatrisanti, H. Gumilang, B. Cahyono, and R. Siregar, "Evaluation condition of transformer based on 
infrared thermography results”, IEEE 9th International Conference on the Properties and Applications of Dielectric Materials, 2009, pp. 1055-1058.

[23] D. Kweon, K. Koo, J. Woo, and Y. Kim, "Hot spot temperature for $154 \mathrm{kV}$ transformer filled with mineral oil and natural ester fluid", IEEE Transactions on Dielectrics and Electrical Insulation, Vol. 19, No. 3, 2012, pp. 1013-1020.

[24] R. Jerrard, "Temperature drop to resistance temperature detector in stator windings of turbine generators”, Power Apparatus and Systems, Part III. Transactions of the American Institute of Electrical Engineers, Vol. 73, No. 1, 1954, pp. 665-670.

[25] Stone G.C., Culbert I., Boulter E.A., and Dhirani H., Electrical insulation for rotating machines: design, evaluation, aging, testing, and repair, The Institute of Electrical and Electronics Engineers Inc., 2014.

[26] K. de Morais Sousa, A. Hafner, M. Crespim, J. Somenzi, V. de Oliveira, H. Kalinowski, and J. da Silva, "Fiber Bragg grating sensing applications in temperature monitoring of three-phase induction motors", SBMO/IEEE MTT-S International Microwave \& Optoelectronics Conference, 2011, pp. 862-866.

[27] G.C. Stone, "Condition monitoring and diagnostics of motor and stator windings - A review", IEEE Transactions on Dielectrics and Electrical Insulation, Vol. 20, Iss. 6, 2013, pp. 2073-2080.

[28] C.-W. Lee, B.-K. Choi, and M.-S. Gong, "Humidity sensitive properties of alkoxysilanecrosslinked polyelectrolyte using sol-gel process", Analyst, Vol. 129, No. 7, 2004, pp. 651-656.

[29] M.P. Zakharich, I.I. Zaitsev, V.P. Komar, F.N. Nikonovich, M.P. Ryzhkov, and I.V. Skornyakova "Analysis of Transformer Oil Using IR Analyzers”, Journal of Applied Spectroscopy, Vol. 68, No. 1, 2001, pp. 61-65.

[30] S. Hvidsten, P. Werelius, and J. Christensen, "Evaluation of on-site dielectric response methods for nondestructive testing of water treed $\mathrm{MV}$ XLPE cables", 16th International Conference and Exhibition on Electricity Distribution. Part 1: Contributions, Vol. 1, 2001, pp. 1.48.

[31] R. Neimanis, and R. Eriksson, "Diagnosis of moisture in oil/paper distribution cables - Part I: Estimation of moisture content using frequencydomain spectroscopy", IEEE Transactions on Power Delivery, Vol. 19, Iss. 1, 2004, pp. 9-14.

[32] "Detection and location of high voltage cable sheath damage with water penetration monitoring”, [Online]. Available: http://www.cablejoints.co.uk/.

[33] Y. Tian, P.L. Lewin, and A.E. Davies, Comparison of on-line partial discharge detection methods for HV cable joints, IEEE Transactions on Dielectrics and Electrical Insulation, Vol. 9, No. 4, 2002, pp. 604-615.
[34] ASTM D3382-07, Standard test methods for measurement of energy and integrated charge transfer due to partial discharges (corona) using bridge techniques, 2007.

[35] ASTM D1868-07, Standard test method for detection and measurement of partial discharge (corona) pulses in evaluation of insulation systems, 2007.

[36] IEC/TS 60034-27, Rotating electrical machines part 27: off-line partial discharge measurements on the stator winding insulation of rotating electrical machines, 2012.

[37] IEC/TS 61934, Electrical insulation systems electrical measurement of partial discharges (PD) under short rise time and repetitive voltage impulses, 2011.

[38] IEEE Std. 4-1995, IEEE Standard techniques for high-voltage testing, 1995.

[39] IEEE Std. 286-2000, IEEE Recommended practice for measurement of power-factor tip-up of rotating machinery stator coil insulation, 2000.

[40] IEEE Std. 433-2009, IEEE Recommended practice for insulation testing of AC electric machinery at very low frequency, 2009.

[41] IEC 60885-2, Electrical test methods for electric cables. Part 2: Partial discharge tests, 1987.

[42] IEC 60885-3, Electrical test methods for electric cables. Part 3: Test methods for partial discharge measurements on lengths of extruded power cables, 1988.

[43] IEEE Std. 400-2012, Guide for field testing and evaluation of the insulation of shielded power cable systems rated $5 \mathrm{kV}$ and above, 2012.

[44] IEEE Std. 400.2-2013, Guide for field testing of shielded power cable systems using very low frequency (VLF)(less than $1 \mathrm{~Hz}$ ), 2013.

[45] IEEE Std. 400.3-2006, Guide for partial discharge testing of shielded power cable systems in a field environment, 2006.

[46] A. Agoston, C. Ötsch, J. Zhuravleva, and B. Jakoby, "An IR-absorption sensor system for the determination of engine oil deterioration", Proceedings of IEEE Sensors, Vol. 1, 2004, pp. 463-466. 